\title{
1. The changing role of law in Japan: empirical studies in culture, society and policy making: an introduction
}

\author{
Dimitri Vanoverbeke, Jeroen Maesschalck, \\ Stephan Parmentier and David Nelken
}

\section{INTRODUCTION}

Parallel to Japan's rise to economic prominence on the world scene in the 1960s, law and legal thinking in the country have become the focus for academic research in various respects. One recurring question has been why Japan managed to become one of the most important economic actors in the world without the legal infrastructure usually associated with complex economic activities.

Many authors (e.g. Kawashima 1959, 1963; Noda 1966; Chiba 1989) have referred to culture and tradition to explain why the role of law is less formalized compared with other major economies. The limited number of lawyers and magistrates, the low crime rate, the absence of contracts and the prominence of informal dispute resolution are just some aspects that surprise legal scholars from outside Japan, particularly when taking its highly advanced global economy into consideration. The role of law in Japan, according to the mainstream scholarly interpretations, remains limited and more state-oriented than citizen- (or client-) oriented for cultural and historical reasons, combined with institutional constraints. Even authors denying the importance of culture in understanding the role of law in Japan were, in doing so, contributing to the prominence of culture in the discourse on the role of law (e.g. Haley 1978; Ramseyer 1988).

However, the widely shared view of the importance of culture is increasingly challenged in the literature and this book aims to offer a contribution to this debate. The book specifically focuses on two important challenges to that classical view.

First of all, it is important to note that most authors referring to culture as an explanation for the (limited) role of law in Japan were either implicitly or explicitly taking the United States as their point of reference. Yet, 
this perspective overlooks the fact that legal institutions and practices of the US only entered Japan after the end of the Second World War. Before 1945 - in the formative period of the legal institutions in Japan-Europe's continental law was the main source of inspiration. The rare studies by European or Japanese authors that do take Europe as a point of reference typically address the role of law from different socio-legal perspectives, emphasizing similarities as well as differences (e.g. Vanoverbeke 2010). The present volume aims to add to this budding line of research. This is not only useful because of the European origins of Japanese legal institutions, but also because both Japan and the EU are moving towards more cooperation, as illustrated by the Free Trade Agreement negotiations (Keck et al. 2013). Both countries are also said to be moving towards a self-proclaimed common approach as 'soft' world powers that emphasize the rule of law as a cornerstone of their foreign policy. A '(re)turn to Europe' in comparative research on the changing role of law in Japan can allow for a more nuanced understanding of similarities and differences between these two major blocs. A number of contributions in this book indeed offer such understanding.

Secondly, traditional perspectives on law in Japan tend to overlook its dynamic character. In the 1990s, the so-called 'lost decade' of Japan, the Japanese economy encountered a severe socio-economic recession. The model of 'Japan as Number One' (Vogel 1979) was challenged from both inside and outside the country. The discourse changed from confidence in 'the Japanese way' to a need for a more global, open, competitive and deregulated approach that would also allow for more responsible individual citizens. Indeed, in the 1990s, more non-Japanese companies entered the market, bankruptcies increased, young entrepreneurs in information technology and related businesses challenged the conventional wisdom, and rising crime rates became subjects of concern. These economic and societal changes in Japan also spilled over to the field of law, as illustrated in at least two dimensions of change. First, major players in the political, economic and legal fields demanded institutional reforms. Reforms of the judiciary were increasingly seen as a way out of the crisis. The introduction of the law schools and of the lay judge system, as well as the reforms of legal aid and the fostering of alternative dispute resolution (ADR), pushed such legal reforms to the level of rapid and drastic changes. This book will document and analyse a number of these developments. Second, the actual reforms of the legal landscape coincided with more discursive, theoretical debates about the changing role of the law in Japan, as exhibited by the popularity of the concept 'legal turn' (hōka 法化) in both common discourse and (socio-)legal research. Many argue that this evolution in discourse also implied genuine changes in the way in which magistrates, 
attorneys, public administrators and other actors approach the law. Others wonder whether the changes were not merely limited to changes in discourse, not in practice. A number of contributions in this book will also add to this debate. Both dimensions of change, some argue, reduce the differences between Japan and other countries, particularly the US. They would make Japan less 'exceptional' and thus reduce the credibility of a cultural explanation concerning the role of law. While some contributions in this book indeed offer evidence of such a convergence, overall the argument seems much more complex.

This volume consists of four major parts. The first is intended to provide the general background against which the changing role of law in Japan can be assessed. In the first and introductory chapter, David Nelken emphasizes that Japanese law has recently been undergoing important social transformations. The country has for a long time been treated as a case study of a society where lawyers, judges and litigation played relatively marginal roles. Some accounted for these features by reference to a 'culturalist' argument on the specific way in which law and formal dispute processing were perceived and lived in Japan (and Asia more generally). Others referred to politically shaped institutional impediments to relying on the courts. The chapter provides the foundation for this volume in exploring the concept 'legal culture' that has taken root in many writings about law in Japan and Asia in general. Nelken analyses the problem of defining and working with the concept and addresses the different approaches for doing so. $\mathrm{He}$ suggests the need to explore more carefully the ideas of 'units', 'elements' and 'aggregates' assumed by the notion of legal culture and concludes by considering where this leaves us with respect to the key issues of cultural coherence and social change. It is important to see that legal culture, like culture in general, is continuously changing and adapting itself to internal and external pressures and challenges. For Nelken, the specific feature of the collection of chapters in this book lies in the way in which the authors seek to apply socio-legal theories and methodologies about the use of law that are also used elsewhere. In doing so, they challenge the uniqueness of Japanese legal culture and its 'way of doing law' and look to the same kinds of variation that are examined by socio-legal scholars everywhere.

In the second chapter Gessner challenges the widely held assumption that the rule of law leads to economic growth. The evidence for this assumption is mixed, and recent debates suggest alternative explanations for economic success. Asian particularities of state-society synergies might play an important role in explaining economic success. He particularly focuses on institutions that combine informal norms and formal law or -in the terminology of social capital discourse - personal and impersonal trust. Against the background of social capital theory, the author 
compares some recent Asian and Western attempts at reforming the legal environment for their respective economies. He criticizes the usual dichotomy of informal mechanisms versus formal law, and instead explores on the one hand the state-society synergy in Japan as constituted through diverse mechanisms, including trust in contractual relations, arrangements between enterprises and their 'main bank', and communal administrative reforms with input from the population. On the other hand, if communicative rationalities are generally among the main characteristics of Asian legal cultures, it is surprising that they do not seem to be influential in the judiciaries. Current judicial reforms in Japan do not seem to follow such synergetic traditions. This is exemplified by the negative attitude of doctrinal procedural law (in the German tradition) against collective actions (which bring the public interest into the court room) and the absence of judicial transparency through access to judicial information and in particular to sources on the Internet. In the aftermath of the corporate and financial scandals, Western countries are also beginning to pay attention to the specifics of state-society synergy and to search for Peerenboom's 'right combination of private and public ordering' in Asian countries and try to learn from them.

Ozaki's chapter is intended to shed new light on the classical question of whether the low litigation rate in Japan is rooted in cultural aspects or is due to other reasons. His starting point lies in the writings of the famous legal scholar Kawashima about the gap between the (modern) Japanese legal or judicial system and the consciousness of ordinary people, and the different interpretations resulting from this dilemma. While some scholars have argued that there is a deterministic, essentialist and unchanging aversive tendency towards law among Japanese people ('cultural thesis'), others propound that this tendency is no more than an artificially and politically induced, changeable and superficial one ('institutional thesis'). In order to re-interpret Kawashima's perspective, Ozaki engages in a critical analysis of the concept of culture as a framework constructed and reconstructed in history to give meanings to actions and reactions of self and others, and everything in the world. Viewing culture as a dynamic reality and grasping its cyclical construction leads to very different conclusions in relation to the reality of Japan. It allows us to see Japanese law and culture in full transition, as illustrated by the rapidly increasing litigation rate, the expansion of the judicial system and the wider use of law in society. Although Japan since the mid-1970s is gradually turning from a law-aversive into a law-using society, it still displays a persistent gap between law and society. In a way, Kawashima's work can be seen as a profound reflection on culture that constituted a prediction of the upcoming changes, rather than an ethnic essentialism sticking to the status quo. 
Vanoverbeke and Suami examine the legal reforms of the start of the twenty-first century (the Heisei judicial reforms), which were intended to implement the recommendations by the Judicial Systems Reform Council. The reforms intended to change the limited role that law was said to have played in Japanese society, thus hoping to overcome the long-lasting socio-economic crisis Japan was experiencing in the 1990s. Lingering doubts about the legitimacy of a 'paternalistic' state was reflected in the discourse on the reform of legal education and on the role of the magistrates in the criminal procedure. The authors point out that two of the main pillars of the judicial reforms - the introduction of the law schools and the introduction of trial by jury (lay judge system) - were ambitious undertakings to change legal culture and bring the judiciary in line with the role of law played in the US and Europe. They also take a closer look at the reform process and the implementation of the reforms. They conclude that the Heisei judicial reforms can rightly be labelled a 'turning point' in the role of law played in Japan but that the implementation of the reforms in the first decade of the twenty-first century did not yet bring all the results policy-makers had hoped for.

The second part of the book focuses on the so-called 'legal turn' and investigates whether and to what extent there is a growing use of law in Japan. Building on the previous chapter's attention to the law and judicial reforms since the 1990s, Kozuka analyses the debtor and credit law and investigates whether the law now plays a more prominent role in today's Japanese society. The author first argues that these new laws were indispensable to stimulate the economy by facilitating the supply of credit to industry. Amending the law on secured transactions and the law on trade credits was essential, not only to restore the strength of the struggling Japanese economy, but also to address spill-over effects of this economic crisis to other sectors in the socio-political sphere. Kozuka argues that these new laws implied a 'legal turn' from informal negotiation to a formal procedure in the debtor-creditor relationship. He explains that this was rather a carefully chosen strategy to cope with the economic crisis than a reform resulting from changing attitudes to the law. Meanwhile, an undercurrent of continuity remains as the parties still rely on informal coordination, convinced that this would guarantee efficiency and speed. In conclusion, a 'turn to law' in debtor-creditor relationships is indeed developing, but it is not complete.

Takahashi for his part argues for a comparative analysis as a way to understand the impact of reforms of laws and legal procedures. He starts with examining the academic debate that has been central to the sociology of law in and on Japan for several decades. The debate not only concerned the definition of concepts such as culture and psychology, institutions 
and politics, but also how these concepts can be used in the scholarly discussion on the role of law in Japan. Takahashi calls for a more rigorous understanding of the concepts that are typically used in generalizing statements of legal behaviour in Japan and demonstrates that a comparative approach can be helpful in this respect. His study analyses alternative dispute resolution (ADR) mechanisms (excluding family-related disputes) in the UK and Japan. While both countries have established new initiatives to promote the use of ADR, they also display many differences. According to Takahashi, the main difference is that in the UK the parties have a strong autonomy in the settlement process involving private 'ADR conductors', while in Japan authorities still provide more formal guidance. In Japan, ADR includes in-court mediation and involves a professional judge in the settlement panel, but the legal turn with respect to the reforms of the ADR procedure remains limited in practice. Takahashi is reluctant to draw general conclusions referring to changing institutions, politics, culture or psychology. Instead, he argues that rigorous and comparative empirical and historical socio-legal research will help to understand different approaches to law and to the judiciary in different settings.

In his contribution, Herber addresses the widely held assumption that Japan is experiencing something like a punitive turn. Traditionally, the Japanese criminal justice system has been described as 'benevolent paternalistic', with significant discretion for prosecutors and judges to suspend prosecution for less serious crimes if they are confessed. More recently, Japan is said to have undergone an evolution towards a harsher treatment of offenders, denoted genbatsuka (厳罰化), as indicated by a number of legal changes towards a more punitive approach. Yet, is that punitive turn also visible on the ground? Are larger proportions of offenders previously diverted from criminal justice processes now indeed processed formally? Are greater proportions of the offenders now formally tried and sent to prison? Herber's analysis of the official figures does not confirm these assumptions. Instead, he identifies a much more nuanced picture, with suspension and sentencing rates diverging across different types of offences. Prosecutors and judges are still exercising their discretion, and not in a clearly punitive way. Herber makes a similar observation in his analysis of the sentencing practices by citizens as part of the lay judge or saiban'in (裁判員) system. This suggests that public opinion also allows for more diversity in its judgements than the easy claims of ever-strengthening genbatsuka suggest.

Similar questions are dealt with in the following and third parts of the book. Here the changing role of legal actors is at the centre of the analysis, as well as the question whether a 'turn to court' can be discerned in Japan. Hirata addresses this question in one specific area. She examines 
how Japanese regulators enforce the Water Pollution Control Act and provides a game-theoretic analysis of what is considered the Japanese informal and cooperative enforcement style, which is apparently prone to avoiding formal legal actions. Based on her in-depth interviews with local regulators, she reaches the conclusion that for more than twenty years no change can be seen. The regulated companies suspected of failing to act in accordance with the Act (about 10 per cent of the visited companies) reply positively to 'administrative guidance' (non-legally binding warning letters) issued by the local administrators. Hirata concludes that the preferred enforcement strategy of informalism is part of the preferred perception of the regulators and regulated. Perhaps this could be described as legal culture? Yet, she also uses game theory to explain why a stable mode of cooperation - an equilibrium - is maintained. All players in this game are 'repeat players', which explains the continuity in enforcement mechanisms. These players value face-to-face communication and are frequently exposed to informal enforcement, resulting in the perception that this is an 'appropriate' way to enforce the law. Both players continue to perceive that such enforcement practice results in the best pay-offs, which in turns explains stability even in times of reforms.

The contribution by Hamano aims at studying the accessibility to the legal system in Japan through the prism of citizens' access to attorneys. The author uses two recent quantitative surveys: (1) a survey in 2000 among parties in civil litigation on the accessibility of attorneys and (2) the Disputing Behaviour Survey of 2005, focusing on the questions concerning the access to attorneys by individuals involved in civil disputes. Relying on both sources, Hamano concludes that when citizens face a justiciable problem, they are more likely to use an attorney to deal with the matter if they have previous experience of using attorneys or have a personal network through which they can reach an attorney. For the first time based on national survey data, these findings have important implications for both theory and practice in Japan and other countries. They also pose a challenge to the newly established Japan Legal Support Centre of 2006. The latter was set up within the wider Judicial Reform movement that intended to enhance access to justice for all, by providing necessary information and services required for legal dispute resolution. Hamano argues that the pattern of access to attorneys in Japan is not only a result of the distinctive nature of legal services but also a product manufactured in the context of Japanese politics and society and its institutional settings.

Another aspect of the use of courts is discussed by Mihira, who observes changes in the previous decade related to judicial review and human rights in the Supreme Court of Japan. The Supreme Court has been criticized in the past for its passive attitude, but Mihira argues that the Supreme 
Court has been changing in a notable way. Yet, differences with European countries and the US continue to exist. Justices in the Supreme Court of Japan are changing to a more activist and dynamic stance. They tend to pay more attention to trends in judicial review and human rights issues in other countries and in international law than in the past. Mihira suggests that the change in the normative context due to the late judicial reform is a prime factor of the Court's recent activism along with the generational shift in the Court's membership. The transformation in the normative context has had constitutive effects on the justices' judicial values and has also functioned as a new normative resource for those justices who see the importance of a more active judiciary. Mihira thus concludes that a generational shift combined with the changing expectations of citizens and politicians helps to account for the shift to the courts and the changing role of the court in contemporary Japan.

The seminal work of Kawashima also inspired Murayama, who is interested in investigating the empirical hypothesis of this grand author about the legal consciousness of the Japanese people as the decisive cause of the small number of lawyers and the low litigation rate in Japan. This traditional Japanese legal consciousness was attributed to attitudes among peasants in agrarian communities, who valued harmony and tried to avoid disputes because of their mutual dependence. According to Kawashima, such attitudes typical for agrarian societies would wither away and the litigation rate would increase as Japanese society became more industrialized. Murayama takes on the challenge of addressing this empirical hypothesis by presenting evidence based on findings of the large national Disputing Behaviour Survey of 2005. His sophisticated analyses do not support the idea that these attitudes, often ascribed to traditional Japan, still exist today. Instead, he finds support for two other hypotheses. First, Japanese citizens' attitudes to law have changed since the 1950s; and second, whatever Japanese citizens' general attitudes are, the impact of these attitudes on problem-solving behaviour is not large in its initial stage and even less in the stage of using the law. Instead of focusing on the cultural attitudes of people using the law, more attention, Murayama argues, should be paid to institutional arrangements to understand Japanese disputing behaviour.

In the final part of this book, three authors compare the role of law in Europe and Japan in specific areas and wonder about the major differences and similarities between the two regions. Vande Walle addresses one specific aspect that is often associated with Japanese legal culture: a supposedly negative attitude towards litigation. His chapter challenges this classical view on Japanese litigiousness through the lens of a specific type of litigation, namely private lawsuits in response to violations of anti- 
trust law. He finds that, while the Japanese are indeed reluctant litigants in this area, the same can be said about the Europeans. Rather than a Japanese exceptionalism, there seems to be an American exceptionalism. He also finds that, more than cultural factors, institutional factors can explain these differences to a great extent: the absence of an opt-out class mechanism in Japan and Europe, the lack of contingency fees for lawyers in Japan and Europe, rules about allocation of court costs, and so on. To the extent that cultural factors do play a role, he suggests that they are malleable and subject to rapid change. This, he argues, is the only way to explain the significant increase in the number of antitrust cases in the past decades in both Japan and Europe.

Van Zimmeren also objects to the 'exceptionalism' claim in the analysis of public policy. Rather than looking for exceptions to a norm, she argues that it is better to compare and look for differences and similarities, which might in turn constitute a basis for mutual learning. In her comparative analysis of the Japanese and European patent systems, she describes a general evolution in both jurisdictions from a static model of patent regulation towards what she describes as 'dynamic patent governance'. The latter implies the involvement of more formal as well as informal actors, including actors from civil society. Yet, she also identifies significant differences between both jurisdictions and suggests that these might be sources of inspiration in mutual learning. For example, the Japanese approach is strongly coordinated, with two specialized intellectual property (IP) institutions developing coherent policies, acting as 'spiders in the web'. This is in sharp contrast to the very complex institutional structure of the European system. The Japanese system, on the other hand, is still relatively weak in involving wider civil society in the governance of the Japanese patent system.

European and Japanese policy-makers often boast about 'shared values', an argument taken as a firm base for the ongoing negotiations to conclude a Free Trade Agreement. In the final chapter of this book, Suami develops this point of view by comparing the practice of judicial review and human rights in Europe and Japan. With respect to judicial review, Suami observes little litigation in Japan. This is ascribed to Japanese citizens' respect for authority as well as a different institutional context for a different practice of judicial review. The author observed similar differences with respect to the concept of human rights. In the constitution of Japan, for example, no positive duties of the state to protect human rights can be found. The author underscores that recent actions in Japan to foster the practice of judicial review and a different approach towards human rights may point at more convergence between Europe and Japan, but that the gap remains wide. He argues in favour of a further Japanese 
turn to Europe in view of the changing role of law in Asia as well as the changing role of Japan in Asia.

This book addresses many current issues that illustrate important changes in Japanese society and its political and legal systems. They investigate fundamental questions about the precise role of law and the courts in Japan, and try to go beyond the classical paradigm that attributes the particularities of Japan to its unique culture or its exceptional position. And although the various contributions to this book cannot provide the final answers to the difficult questions posed, they all demonstrate the importance of challenging old conceptions and revisiting them through meticulous socio-legal and empirical research. By doing so, they invite all readers of this book to think along and contribute their own understanding to the complexity of the central topics.

The editors of this book would like to thank all those who supported and helped actively with writing and assembling this book. They are, in the first place, all the authors of this book, who wrote their chapters in a timely manner and patiently accepted the editors' requests for adjustments related to the central topic of the book. Our thanks also go to the participants of the four international seminars on the dynamics of law and society in Europe and Japan. Starting in 2007 in Leuven, these seminars were held annually, alternatively in Belgium (KU Leuven) and in Japan (Rikkyo University). The Fourth International Seminar on the Dynamics of Law and Society in Europe and Japan (March 2010), entitled Legal Reform and the Role of the Judiciary: Revisiting Japanese Exceptionalism from a European Perspective, was the starting point of the project resulting in the current book. We would in particular like to thank the Japan Foundation for the funding provided, which made the academic exchange among European and Japanese socio-legal scholars possible. We also would like to express our appreciation for the efforts of Nicholas Peeters and David De Cooman, who helped at various stages in the preparation of the manuscript of this book.

\section{REFERENCES}

Chiba, Masaji (1989), Legal Pluralism: Toward a General Theory through Japanese Legal Culture, Tokai University Press.

Haley, John Owen (1978), 'The myth of the reluctant litigant', Journal of Japanese Studies, 4 (2), 359-90.

Kawashima Takeyoshi川島武宜 (1959), ‘Junpō seishin' 遵法精神 [Law-abiding spirit], in Kindai shakai to hō 近代社会と法 [Modern society and the law], Tokyo: Iwanami Shoten 岩波書店, pp. 55-117.

Kawashima, Takeyoshi (1963), 'Dispute resolution in contemporary Japan', in 
Arthur T. von Mehren (ed.), Law in Japan: The Legal Order in a Changing Society, Cambridge, Mass: Harvard University Press; Tokyo: Charles E Tuttle Company, pp.41-72.

Keck, Jörn, Dimitri Vanoverbeke and Franz Waldenberger (eds) (2013), EU-Japan Relations, 1970-2012: From Confrontation to Global Partnership, Routledge Contemporary Japan Series.

Noda, Yoshiyuki (1966), Introduction au droit japonais, Paris: Dalloz.

Ramseyer, Mark (1988), 'Reluctant litigant revisited: Rationality and disputes in Japan', Journal of Japanese Studies, 14 (1), 111-23.

Vanoverbeke, Dimitri (2010), Recht en instellingen in Japan: Actuele thema's in een historische context. Leuven/Den Haag: ACCO.

Vogel, Ezra F. (1979), Japan as Number One: Lessons for America, Harvard University Press. 
Dimitri Vanoverbeke, Jeroen Maesschalck, Stephan Parmentier, and David Nelken - 9781783475650 Downloaded from PubFactory at 04/26/2023 09:36:10AM 